\title{
Formulasi Sediaan Gel Dari Ekstrak Etanol Herba Pegagan (Centella asiatica (L) Urb)
}

\author{
Nurlatifah $^{1}$, Lidyawati ${ }^{1, *}$, Rosa Mardiana ${ }^{1}$, Dwi Putri Rejeki ${ }^{1}$, Mona Asiah ${ }^{2}$ \\ ${ }^{1}$ Program Studi Farmasi, Akademi Farmasi YPPM Mandiri, Banda Aceh, Indonesia \\ ${ }^{2}$ Fakultas Matematika dan Ilmu Pengetahuan Alam Program Studi Farmasi, Universitas Syiah Kuala, Banda Aceh, Indonesia \\ Email: Lidyawati.mpipa@gmail.com
}

\begin{abstract}
Abstrak-Indonesia merupakan negara yang kaya ditinjau dari keanekaragaman flora maupun fauna. Kekayaan Indonesia dengan berbagai jenis flora merupakan sorotan bagi ilmu pengetahuan, salah satunya adalah herba pegagan (Centella asiatica (L) Urb). Senyawa kimia asiatikosida merupakan bagian dari triperoid yang terkandung didalam herba pegagan berpotensi sebagai antibakteri, anti jamur, antioksidan dan antiselulit pada kulit cocok dijadikan sediaan topikal seperti gel. Penelitian ini bertujuan untuk memformulasikan sediaan gel dari ekstrak etanol herba pegagan (Centella asiatica (L) Urb) yang memenuhi persyaratan gel yang baik. Formulasi sediaan gel dilakukan dengan konsentrasi 20\%, 25\%, dan 30\%. Diekstraksi dengan metoda maserasi menggunakan etanol $70 \%$ dan di vacum rotary evapolator untuk mendapatkan ekstrak kental. Evaluasi sediaan gel dilakukan dengan uji organoleptis, uji homogenitas, uji pH, uji daya sebar, uji daya lekat dan uji iritasi. Hasil evaluasi yang dilakukan dengan tiga konsentrasi tersebut memenuhi persyaratan uji organoleptis, uji homogenitas, uji $\mathrm{pH}$, uji daya lekat dan uji iritasi, namun gel ekstrak etanol herba pegagan pada konsentrasi $20 \%, 25 \%$ dan 30\% tidak memenuhi syarat untuk uji daya sebar yang baik.
\end{abstract}

Kata kunci: Formulasi; Ekstrak; Herba Pegagan; Gel

\begin{abstract}
Indonesia is a rich country in terms of flora and fauna diversity. Indonesia's wealth with various types of flora is a highlight for science, one of which is the gotu kola herb (Centella asiatica (L) Urb). The chemical compound asiaticoside is part of the triperoids contained in the gotu kola herb which has the potential as antibacterial, antifungal, antioxidant and anti-cellulite on the skin, suitable for topical preparations such as gels. This study aims to formulate a gel preparation from the ethanolic extract of the gotu kola herb (Centella asiatica (L) Urb) which meets the requirements of a good gel. The formulation of the gel preparation was carried out with concentrations of $20 \%, 25 \%$, and $30 \%$. Extracted by maceration method using $70 \%$ ethanol and in a vacuum rotary evaporator to obtain a thick extract. Evaluation of the gel preparation was carried out by organoleptic test, homogeneity test, pH test, dispersibility test, adhesion test and irritation test. The results of the evaluation carried out with the three concentrations met the requirements of the organoleptic test, homogeneity test, $\mathrm{pH}$ test, adhesion test and irritation test, but the ethanol extract gel of the gotu kola herb at concentrations of $20 \%, 25 \%$ and $30 \%$ did not meet the requirements for the good dispersion test.
\end{abstract}

Keywords: Formulations; Extracts; Gotu Kola Herbs; Gel

\section{PENDAHULUAN}

Indonesia merupakan negara yang kaya ditinjau dari keanekaragaman flora maupun fauna. Kekayaan alam Indonesia dengan berbagai jenis flora merupakan sorotan bagi ilmu pengetahuan. Tumbuhan merupakan salah satu kekayaan yang tiada ternilai karena manfaatnya yang cukup besar dalam kehidupan, salah satunya adalah sebagai obat yang telah digunakan oleh masyarakat luas. Pada hakikatnya, walaupun zaman sudah modern dan banyak diciptakannya obat sintetis, namun pasti kembali lagi pada alam, banyak masyarakat yang telah menggunakan berbagai tanaman untuk dijadikan obat, salah satunya adalah herba pegagan (Centalla asiatica $(\mathrm{L}) \mathrm{Urb})$.

Herba pegagan (Centella asiatica (L) Urb) adalah salah satu tanaman yang tumbuh ditempat yang terbuka, pada tanah lembab dan subur seperti di pematangan sawah, di padang rumput, di pinggir parit dan sering digunakan untuk pengobatan tradisional, seperti untuk obat diare, disentri dan juga untuk melembabkan kulit (Orhan IE.,2012).

Salah satu kandungan herba pegagan (Centella asiatica (L) Urb) yaitu asiatikosida yang berfungsi mempercepat dan memicu pertumbuhan kolagen pada bagian kulit, sehingga bisa memperbaiki dan membuat regenerasi kulit ketika terjadi kerusakan kulit (Sikareepaisan et al., 2008).

Beberapa penelitian telah dilakukan untuk mengetahui aktivitas pegagan sebagai antimikrob, antifungi, dan antioksidan (Lee \& Vairappan, 2011), serta antikanker (Kim et al., 2009). Penggunaan herba pegagan sebagai obat penyembuh luka bakar dapat dipermudah dengan memformulasikannya dalam sediaan gel. Kandungan air yang tinggi dalam basis gel dapat menyebabkan terjadinya hidrasi pada stratum corneum sehingga akan memudahkan penetrasi obat melalui kulit (Kibbe, 2004).

\section{METODOLOGI PENELITIAN}

Penelitian ini menggunakan metode eksperimen, yakni pembuatan formulasi sediaan gel ekstrak etanol herba pegagan (cetella asiatica (L).Urb). Telah dilaksanakan pada bulan juni 2021 sampai Agustus 2021 di Laboratorium FMIPA USK Banda Aceh dan laboratorium farmasetika Akademi Farmasi YPPM Mandiri Banda Aceh.

Alat yang digunakan dalam penelitian ini adalah timbangan digital, wadah maserasi, batang pengaduk, spatula, vakum rotary evaporator, pipet tetes, corong kaca, pot plastik, kertas perkamen, objek glass, pH meter, kertas saring, stamfer, blender, cawan porselin, gelas ukur $50 \mathrm{ml}$, beaker glass $250 \mathrm{ml}$, lumpang, mortar, erlenmayer $250 \mathrm{ml}$.

Bahan-bahan yang digunakan dalam penelitian ini adalah ekstrak pegagan, Na CMC, gliserin, propilen glikol, metil paraben, etanol $70 \%$ dan aquadest. 


\section{Journal of Pharmaceutical and Health Research}

Vol 3, No 1, Februari 2022, pp. 10-14

ISSN 2721-0715 (media online)

DOI 10.47065/jharma.v3i1.1366

\subsection{Determinasi tanaman}

Determinasi tanaman dilakukan di Laboratorium FMIPA Universitas Syiah Kuala Banda Aceh.

\subsection{Penyiapan Simplisia}

Penyiapan bahan dilakukan dengan mengumpulkan daun pegagan kemudian daun yang sudah terkumpul dari desa Suwiek kecamatan Indra Jaya Kabupaten Pidie, sebanyak 4 kg dihilangkan kotorannya dengan air mengalir hingga bersih lalu ditiriskan. Selanjutnya, daun pegagan dikeringkan dibawah sinar matahari dan ditutupi permukaannya dengan kain hitam hingga 3-4 hari hingga menjadi simplisia kering.

\subsection{Ekstraksi Herba Pegagan}

Proses ekstraksi dilakukan dengan metode maserasi. Pertama daun pegagan dihaluskan dengan blender hingga menjadi serbuk halus. Serbuk halus kemudian direndam dalam pelarut etanol $70 \%$ dengan perbandingan antara serbuk halus dan pelarut adalah 1:10. Proses maserasi dilakukan selama 5 hari yang dilanjutkan dengan remaserasi selama 2 hari yang bertujuan untuk menarik sisa zat aktif yang belum larut dalam etanol saat proses maserasi. Selama maserasi, sesekali serbuk digojog agar penyarian sempurna. Setelah 5 hari, rendaman serbuk disaring dan dipisah antara filtrat dengan ampas yang terbentuk. Filtrat yang telah dipisah akan diuapkan dengan rotary evaporator sampai terbentuk ekstrak kental. Sedangkan ampas yang terbentuk selanjutnya diremaserasi selama 2 hari. Proses untuk mendapatkan ekstrak kental dari remaserasi sama seperti pada proses maserasi.

\subsection{Formulasi Gel}

Formulasi basis gel dapat dilihat pada tabel 1.

Tabel 1. Formulasi Basis Gel

\begin{tabular}{cc}
\hline Bahan yang digunakan & Jumlah bahan yang digunakan \\
\hline Na CMC & $5 \%$ \\
Gliserin & $10 \%$ \\
Propilen Glikol & $5 \%$ \\
Metil paraben & $0,2 \%$ \\
Aquadest ad & $50 \mathrm{gr}$ \\
\hline
\end{tabular}

Sumber: Hamzah,dkk (2006)

\subsection{Pembuatan Basis Gel}

1. Na CMC ditaburkan diatas air panas (20 kali berat $\mathrm{Na} \mathrm{CMC}$ ), dibiarkan sampai mengental lalu digerus sampai homogen (M1).

2. Metil paraben dilarutkan dalam propilen glikol, selanjutnya ditambahkan gliserin dan gerus hingga homogen (M2).

3. (M2) kemudian dimasukkan kedalam (M1) kemudian digerus sampai homogen.

4. Ditambahkan aquadest sedikit demi sedikit, digerus sampai terbentuk gel yang homogen.

5. Ditambahkan sisa aquadest sedikit demi sedikit ke dalam basis gel yang telah terbentuk, dan digerus sampai homogen. Formula gel ekstrak etanol herba peagan dapat dilihat pada tabel 2.

Tabel 2. Formula Gel Ekstrak Herba Pegagan

\begin{tabular}{lccccc}
\hline \multirow{2}{*}{ No } & \multirow{2}{*}{ Bahan } & \multicolumn{4}{c}{ Jumlah Bahan $(\%)$} \\
\cline { 3 - 5 } & & $\mathrm{F} 0$ & $\mathrm{~F} 1$ & $\mathrm{~F} 2$ & $\mathrm{~F} 3$ \\
\hline 1. & Ekstrak herba pegagan & - & $20 \%$ & $25 \%$ & $30 \%$ \\
2. & Na CMC & $5 \%$ & $5 \%$ & $5 \%$ & $5 \%$ \\
3. & Gliserin & $10 \%$ & $10 \%$ & $10 \%$ & $10 \%$ \\
4. & Propilen glikol & $5 \%$ & $5 \%$ & $5 \%$ & $5 \%$ \\
5. & Metil paraben & $0.2 \%$ & $0,2 \%$ & $0,2 \%$ & $0,2 \%$ \\
6. & Aquadest ad (gr) & 50 & 50 & 50 & 50 \\
\hline
\end{tabular}

Keterangan :

F0 : Basis gel

F1 : Gel Ekstrak herba Pegagan 20\%

F2 : Gel Ekstrak herba Pegagan 25\%

F3 : Gel Ekstrak herba Pegagan 30\%.

\subsection{Evaluasi Sediaan Gel dari Ekstrak Etanol Herba Pegagan}

1. Uji organoleptis

Pengujian organoleptis dengan melakukan pengamatan terhadap bentuk, warna dan bau dari sediaan yang telah dibuat Uji homogenitas (Anief.,2007).

2. Uji homogenitas 


\section{Journal of Pharmaceutical and Health Research}

\section{Vol 3, No 1, Februari 2022, pp. 10-14}

ISSN 2721-0715 (media online)

DOI 10.47065/jharma.v3i1.1366

Uji homogenitas dilakukan dengan cara mengoleskan gel sebanyak 0,5 gram pada sekeping kaca atau bahan transparan lain yang cocok (Depkes RI .,1997).

3. Uji pH sediaan

Pengukuran nilai $\mathrm{pH}$ menggunakan alat bantu $\mathrm{pH}$ meter yang dicelupkan ke dalam 0,5 gram gel yang telah diencerkan dengan $5 \mathrm{ml}$ aquadest. Nilai $\mathrm{pH}$ gel yang baik adalah 4,5-6,5 (Tranggono dan Latifa.,(2007).

4. Uji daya sebar

Gel ditimbang sebanyak 0,5 gram, kemudian diletakkan ditengah kaca transparan, di atas gel diletakkan kaca transparan lain dan pemberat sehingga berat kaca transparan dan pemberat 100 gram, didiamkan selama 1 menit, kemudian dicatat diameter penyebarannya. Daya sebar gel yang baik anatar 5-7 cm (Mappa.,2013).

5. Uji Daya Lekat

Uji daya lekat dilakukan dengan mengambil sejumlah 0,5 gram gel yang diletakkan pada kaca objek dan kemudian ditutup dengan kaca objek yang lain. Kaca objek ditekan dengan beban berat 100 gram selama 5 menit. Beban kemudian diangkat dan kaca objek dipasang pada alat uji daya lekat. Alat uji diberi beban 8 gram kemudian dicatat waktu pelepasan gel antara 2 kaca objek tersebut (Arista, 2013).

6. Uji iritasi

Sediaan gel dioleskan pada punggung tangan, ditunggu selama 20-30 menit gel dibersihkan. Dilihat hasilnya, apakah aman untuk digunakan atau tidak. Jika tidak menimbulkan iritasi pada kulit, maka gel tersebut dapat digunakan untuk kulit (Masluhiya et al., 2016).

\section{HASIL DAN PEMBAHASAN}

\subsection{Evaluasi Sediaan Gel}

Hasil evaluasi sediaan gel ekstrak etanol herba pegagan meliputi uji organoleptis, uji homogenitas, uji pH, uji daya sebar, uji daya Lekat, dan uji iritasi.

\section{Hasil Uji Organoleptis}

Data hasil uji organoleptis dapat dilihat pada tabel 3.

Tabel 3. Hasil Pengamatan Uji organoleptik

\begin{tabular}{ccccc}
\hline Formula & Warna & Bentuk & Bau & tekstur \\
\hline F0 & Putih & Semi Padat & Tidak bau & Lembut \\
F1 & Hijau & Semi Padat & Bau Khas & Lembut \\
F2 & Hijau & Semi Padat & Bau Khas & Lembut \\
F3 & Hijau pekat & Semi Padat & Bau Khas & Lembut \\
\hline
\end{tabular}

Keterangan :

F0 : Basis Gell

F1 : Formulasi gel ekstrak herba pegagan dengan konsentrasi $20 \%$

F2 : Formulasi gel ekstrak herba pegagan dengan konsentrasi $25 \%$

F3 : Formulasi gel ekstrak herba pegagan dengan konsentrasi $30 \%$

Berdasarkan pada tabel 3 di atas, diperoleh hasil uji organoleptik yaitu pada formula F0 (basis) memiliki warna putih bening berbentuk semi padat dengan tekstur lembut dan tidak berbau. Formula I memiliki warna hijau berbentuk semi padat dengan tekstur lembut dan memiliki bau khas pegagan. Formula II memiliki warna hijau berbentuk semi padat dengan tekstur lembut dan memiliki bau khas pegagan. Formula III memiliki warna hijau pekat berbentuk semi padat tekstur lembut dan memiliki bau khas pegagan. Pada uji organoleptis ini dapat diketahui bahwa dengan penambahan ekstrak herba pegagan dapat mempengaruhi perbedaan warna pada sediaan, semakin banyak penambahan ekstrak herba pegagan maka semakin pekat warna sediaan.

2. Hasil uji Homogenitas

Data hasil uji homogenitas dapat dilihat pada tabel 4.

Tabel 4. Hasil Pengamatan Uji homogenitas

\begin{tabular}{lll}
\hline Formula & Pengamatan & Keterangan \\
\hline F0 & Tidak Ada Butiran Kasar & Homogen \\
F1 & Tidak Ada Butiran Kasar & Homogen \\
F2 & Tidak Ada Butiran Kasar & Homogen \\
F3 & Tidak Ada Butiran Kasar & Homogen \\
\hline
\end{tabular}

Uji homogenitas berdasarkan tabel 4 menunjukkan bahwa F0 (basis), FI, FII dan FIII memiliki susunan yang homogen. Hal ini ditandai dengan tidak adanya partikel-partikel asing dan butiran kasar dalam sediaan, sehingga pada uji homogenitas sediaan gel dapat dikatakan memenuhi syarat uji mutu fisik sediaan.

\section{Hasil uji pH}

Data hasil uji pH dapat dilihat pada tabel 5. 
Journal of Pharmaceutical and Health Research

Vol 3, No 1, Februari 2022, pp. 10-14

ISSN 2721-0715 (media online)

DOI 10.47065/jharma.v3i1.1366

Tabel 5. Hasil Uji pH

\begin{tabular}{cc}
\hline Formulasi & Uji $\mathrm{pH}$ \\
\hline F0 & 4,5 \\
FI & 6,5 \\
FII & 5 \\
FIII & 6 \\
\hline
\end{tabular}

Hasil pengujian pH sediaan gel menggunakan ekstrak herba pegagan menunjukkan bahwa F0 (basis) memiliki pH 4,5 , formula I memiliki pH 6,5, formula II memiliki pH 5, dan formula III 6. Formula 0 sampai III memenuhi syarat evaluasi $\mathrm{pH}$ sediaan gel yang baik, karena $\mathrm{pH}$ sediaan yang dihasilkan mendekati $\mathrm{pH}$ fisiologis kulit yaitu 4,0-6,5.

4. Uji Daya Sebar

Data hasil uji daya sebar dapat dilihat pada tabel 6.

Tabel 6. Hasil Uji Daya Sebar

\begin{tabular}{cc}
\hline Formula & Uji Daya Sebar \\
\hline F0 & $4,9 \mathrm{~cm}$ \\
FI & $4,7 \mathrm{~cm}$ \\
FII & $4,5 \mathrm{~cm}$ \\
FIII & $4,0 \mathrm{~cm}$ \\
\hline
\end{tabular}

Pemeriksaan daya sebar gel menunjukkan bahwa sediaan mempunyai kemampuan daya sebar yang kurang baik dengan F0 (4,9cm), FI (4,7cm), FII $(4,5 \mathrm{~cm})$, FIII $(4,0 \mathrm{~cm})$.

5. Uji Daya Lekat

Data hasil daya sebar dapat dilihat pada tabel 7.

Tabel 7. Hasil Uji Daya Lekat

\begin{tabular}{cc}
\hline Formula & Uji Daya Lekat \\
\hline F0 & 2 detik \\
FI & 4 detik \\
FII & 2,5 detik \\
FIII & 2 detik \\
\hline
\end{tabular}

Pemeriksaan daya lekat gel menunjukkan bahwa sediaan mempunyai kemampuan daya lekat yang bagus dengan F0 2 detik, Formula I memiliki daya lekat 4 detik, formula II memiliki daya lekat 2,5 detik dan formula III memilki daya lekat 2 detik, dan pada saat dioleskan pada punggung tangan dapat menempel pada punggung tangan.

6. Uji Iritasi

Data hasil uji iritasi dapat dilihat pada tabel 8.

Tabel 8. Hasil Uji Iritasi

\begin{tabular}{cccccc}
\hline \multirow{2}{*}{ Formula Gel } & \multicolumn{5}{c}{ Iritasi } \\
\cline { 2 - 6 } & 1 & 2 & 3 & 4 & 5 \\
\hline F 0 & - & - & - & - & - \\
FI & - & - & - & - & - \\
FII & - & - & - & - & - \\
F III & - & - & - & - & - \\
\hline
\end{tabular}

Uji iritasi dilakukan pada 5 sukarelawan uji, dengan cara mengoleskan gel ekstrak herba pegagan pada punggung tangan dan diamati selama 20-30 menit. Dari 5 sukarelawan uji tidak mengalami gejala iritasi yang berupa kemerahan, gatal-gatal, bengkak, terlalu panas dan perih pada permukaan kulit setelah dioleskan sediaan gel yang mengandung ekstrak etanol herba pegagan yang diamati selama 24 jam. Hal ini dikarenakan $\mathrm{pH}$ sediaan salep yang dihasilkan sesuai dengan $\mathrm{pH}$ yang dapat ditolerir oleh kulit yaitu 4,5-6,5.

\subsection{Pembahasan}

Simplisia yang digunakan dalam penelitian ini adalah herba pegagan (Centella asiatica (L).Urb) yang diambil dari desa Suwiek kecamatan Indra jaya kabupaten Pidie. Herba pegagan yang telah dikumpulkan sebanyak $4 \mathrm{~kg}$ disortir dan setelah proses penyortiran didapatkan $2 \mathrm{~kg}$ herba pegagan yang layak uji, lalu dicuci bersih menggunakan air untuk menghilangkan kotoran, dirajang dan dijemur dibawah sinar matahari hingga kering kemudian simplisia yang sudah kering di blender hingga halus.

Pembuatan ekstrak herba pegagan pada penelitian ini dilakukan dengan perbandingan $1: 10$ menggunakan metode maserasi. Pemilihan metode ini karena merupakan salah satu metode ekstrak yang paling mudah, sederhana dan tidak memerlukan alat khusus. Pelarut yang digunakan untuk mengekstraksi herba pegagan (Centella asiatica (L).Urb) yaitu alkohol $70 \%$ karena larutan ini merupakan larutan yang lebih selektif dan tidak berbahaya. Setelah dilakukan proses 


\section{Journal of Pharmaceutical and Health Research}

\section{Vol 3, No 1, Februari 2022, pp. 10-14}

ISSN 2721-0715 (media online)

DOI 10.47065/jharma.v3i1.1366

pengentalan ekstrak menggunakan Vacuum rotary evaporator ternyata pelarut dapat menguap dengan baik dan menghasilkan ekstrak kental berwarna hijau pekat sebanyak 37,2 gram, selanjutnya dibuat sediaan gel ekstrak herba pegagan dengan 3 konsentrasi yaitu F1 20\%, FII 25\%, FIII 30\%.

Pembuatan sediaan gel ekstrak herba pegagan (Centella asiatica (L).Urb) pada penelitian ini bertujuan untuk mengetahui apakah ekstrak dapat dibuat dalam sediaan gel. Sediaan gel yang telah dibuat harus melewati beberapa uji evaluasi diantaranya meliputi uji organoleptis, uji homogenitas, uji pH, uji daya lekat, uji daya sebar dan uji iritasi.

Pengujian homogenitas yaitu pengujian dengan cara diambil 0,5 gram di oleskan pada sekeping kaca atau bahan transparan lain yang cocok, sediaan harus menunjukkan susunan yang homogen dan tidak terlihat butiran kasar. Pengamatan uji homogenitas sediaan gel menunjukkan sediaan tidak terlihat butiran kasar dan partikel asing.

Pengujian pH pada sediaan gel ekstrak herba pegagan (Centella asiatica (L).Urb) bertujuan untuk mengetahui tingkat keasaman dan kebasaan dari sediaan gel yang telah dibuat. Menurut Tranggono dan Latifa (2007), gel yang aman dan baik digunakan pada kulit adalah gel yang memiliki pH sama dengan kulit yaitu 4,0-6,5. Sediaan dengan pH terlalu asam dapat mengiritasi kulit sedangkan $\mathrm{pH}$ yang terlalu basa dapat membuat kulit menjadi kering. Hasil pengujian $\mathrm{pH}$ selama penyimpanan 24 jam pada F0 4,5, formula I memiliki pH 6,5, Formula II memiliki pH 5, dan formula ke III memiliki pH 6, sesuai dengan kriteria uji pH.

Pengujian daya sebar yaitu pengujian yang dilakukan dengan cara mengambil 0,5 gram sediaan gel dioleskan pada kaca transparan, lalu di atas gel diletakkan kaca transparan lain dan pemberat, didiamkan selama 1 menit. Diameter sebar gel diamati dan di ukur, ternyata pada evaluasi uji daya sebar tidak memenuhi kriteria daya sebar gel yang baik karena dari hasil semua formula diameter daya sebar di bawah $5 \mathrm{~cm}$.

Pengujian daya lekat yaitu pengujian yang dilakukan terhadap masing-masing formula yang telah dibuat dengan cara mengoleskan sediaan pada kaca transparan dan di lekatkan dengan kaca transparan yang lainnya dan diberi beban di atasnya , lalu di hitung daya lekatnya menggunakan stopwatch. Pengujian ini dilakukan bertujuan untuk mengetahui daya lekat gel pada kulit. Hasil evaluasi daya lekat pada sediaan gel ekstrak etanol herba pegagan ini memenuhi kriteria uji karena sediaan gel dapat melekat pada kaca, demikian juga pada saat dioleskan pada punggung tangan juga gel dapat melekat.

Uji iritasi dilakukan pada 5 sukarelawan uji, dengan cara mengoleskan gel ekstrak herba pegagan pada punggung tangan dan diamati selama 20-30 menit. Dari 5 sukarelawan uji tidak mengalami gejala iritasi yang berupa kemerahan, gatal-gatal, bengkak, terlalu panas dan perih pada permukaan kulit setelah dioleskan sediaan gel yang mengandung ekstrak etanol herba pegagan yang diamati selama 24 jam. Hal ini dikarenakan $\mathrm{pH}$ sediaan salep yang dihasilkan sesuai dengan $\mathrm{pH}$ yang dapat ditolerir oleh kulit yaitu 4,0-6,5.

\section{KESIMPULAN}

Berdasarkan hasil penelitian yang telah dilakukan terhadap formulasi dan evaluasi sediaan gel ekstrak etanol herba pegagan (Centella asiatica (L).Urb) dapat disimpulkan bahwa ekstrak herba pegagan (Centella asiatica (L).Urb) dapat diformulasikan dalam bentuk sediaan gel. Evaluasi sediaan gel mendapatkan hasil homogen, $\mathrm{pH}$ dan daya lekat serta uji iritasi memenuhi persyaratan gel yang baik, namun dari segi uji daya sebar tidak memenuhi kriteria daya sebar gel yang baik.

\section{DAFTAR PUSTAKA}

Anief, M. (2007). Ilmu Meracik Obat. Gadjah Mada University Press, Yogyakarta.

Arista, Y., Kumesan, N., Yamlean, P. V. Y., dan Supriati, H. S. (2013). Formulasi Dan Uji Aktivitas Gel Antijerawat Ekstrak Umbi Bakung (Crinum Asiaticum L.) Terhadap Bakteri Staphylococcus Aureus Secara in Vitro. PHARMACON Jurnal Ilmiah Farmasi - UNSRAT, 2(02), 2302-2493.

Departemen Kesehatan Republik Indonesia.(1997). Farmakope Indonesia Edisi III. Departemen Kesehatan Republik Indonesia, Jakarta.

Kibbe, A. H. (2004). Handbook of Pharmaceutical Exipients, Third Edition, 18-19, 462-469, 629-631, Pharmaceutikal Press, London.

Kim, W. J., Kim, J., Veriansyah B., Kim, J. D., Lee, S. G. \& Winata, R. R. T. (2009). Extraction of Bioactive Components from Centella asiatica Using Subcritical Water, The Journal of Supercritical Fluid, 48, 211-216.

Lee, T. K. \& Vairappan C. S. (2011). Antioxidant, Antibacterial and Cytotoxic Activities of Essential Oils and Ethanol Extracts of Selected South East Asian Herbs, J Med Plant Res, 5 (21), 5284-5290.

Mappa T, Edy HJ, Kojong N. (2013).Formulasi gel ekstrak daun sasaladahan (Peperomia pellucida (L.) H.B.K) dan uji efektivitasnya terhadap luka bakar pada kelinci (Oryctolagus cuniculus). Jurnal Ilmiah Farmasi. 2(2):49-55.

Masluhiya, AF. Swaidatul.(2016). Formulasi masker alami berbahan dasarbengkoang dan jintan hitam untuk mengurangi kerutan pada kulit wajah. Jurnal Care. Vol.4. hal 26.

Orhan IE. (2012). Centella asiatika (L) Urban: from tradisional medicine to modern medicine with neuroprotective potential. Evid Based Complement AlternatMed.

Sikareepaisan, P., Suksamrarn, A. \& Supaphol, P. (2008). Electrospun Gelatin Fiber Mats Containing A Herbal Centella asiatica Extract and Release Characteristic of Asiaticoside. Nanotechnology; 19; 1-10.

Tranggono IR., Latifah. (2007). Buku Pegangan Ilmu Pengetahuan Kosmetika. Jakarta: PT. Gramedia Pustaka Utama. 